Pacific Journal of Mathematics

ON PARACOMPACTNESS 


\section{ON PARACOMPACTNESS}

\section{HisAHIRO TAMANO}

It is well known that the product of a paracompact space with any compact space is paracompact and hence normal ${ }^{1}$. In this paper, we will establish the converse of this proposition by showing that if $X \times \beta X$ is normal, then $X$ is paracompact (Theorem 2) ${ }^{2}$.

The existence of a compactification is a characteristic property of a Tychonoff space, and the Stone-Čech compactification (the largest one) may reasonably be expected to play an important role in the theory of Tychonoff space. Indeed, some properties of a Tychonoff space $X$ can be characterized by the properties of the Stone-Cech compactification $\beta X$ (more precisely, by the properties of $X$ as a dense subspace of $\beta X)^{3}$, and we shall give a new characterization of paracompactness in $\S 2$ (Corollary of Theorem 1). In Theorem 1, we shall characterize paracompactness by the property of $\beta X \times \beta X$ in connection with the uniformity for $X$. This will yield an easy proof of the main theorem (Theorem 2).

1. Regularly open sets ${ }^{4}$. In the first place, we shall establish a lemma concerning regularly open sets, which will be used in the sequel. Let $A$ be a subset of a topological space $X$. We shall denote by $\mathrm{Cl}_{X}(A)$ the closure of $A$ and by $\operatorname{Int}_{X}(A)$ the interior of $A$.

A subset $A$ of a topological space $X$ is said to be regularly open if and only if $\operatorname{Int}_{X}\left(\mathrm{Cl}_{X}(A)\right)=A$. It is easy to verify that the intersection of two regularly open sets is again regularly open, but the union of them is, in general, not regularly open. The following lemma states that if $X$ is a dense subspace of a topological space $Y$, then the family of all regularly open sets in $X$ is in one to one correspondence with the family of all regularly open sets in $Y$.

Lemma. Let $X$ be a dense subspace of a topological space $Y$.

(a) If $A$ is regularly open in $Y$ then the restriction $A \cap X$ of $A$ on $X$ is regularly open in $X$. Conversely, any regularly open set $B$ in $X$ is identical with the restriction of some regularly open set in $Y$.

(b) Let $A$ be a regularly open set in $Y$ and let $A^{\prime}$ be any open set in $Y$ such that $A \cap X \supset A^{\prime} \cap X$, then $A \supset A^{\prime}$. Therefore two regularly open sets $A, A^{\prime}$ in $Y$ are identical if and only if $A \cap X=$ $A^{\prime} \cap X$.

* Received July 23, 1959.

1 See, [4], Th. 5 and Th. 1.

2 For [the] related results, the reader should refer to $[\mathbf{1}],[\mathbf{3}],[\mathbf{5}]$ and $[\mathbf{8}]$.

3 C.f. [6], p. 96 and p. 97, [7], Th. 28, [11], p. 84 and [9].

${ }^{4}$ C.f. $[\mathbf{1 2}]$. 
Proof of (a). An easy calculation shows that if $X$ is a dense subspace of $Y$, then $\operatorname{Int}_{X}\left(\mathrm{Cl}_{X}(A)\right)=\operatorname{Int}_{Y}\left(\mathrm{Cl}_{Y}(A)\right) \cap X$. Therefore we have $A \cap X \subset \operatorname{Int}_{X}\left(\mathrm{Cl}_{X}(A \cap X)\right)=\operatorname{Int}_{Y}\left(\mathrm{Cl}_{Y}(A \cap X)\right) \cap X \subset \operatorname{Int}_{Y}\left(\mathrm{Cl}_{Y}(A)\right) \cap X=$ $A \cap X$, and it follows that $\operatorname{Int}_{X}\left(\mathrm{Cl}_{X}(A \cap X)\right)=A \cap X$. Hence $A \cap X$ is regularly open. If $B$ is regularly open in $X$, then $B=\operatorname{Int}_{X}\left(\mathrm{Cl}_{X}(B)\right)$ $=\operatorname{Int}_{Y}\left(\mathrm{Cl}_{Y}(B)\right) \cap X$ and $\operatorname{Int}_{Y}\left(\mathrm{Cl}_{Y}(B)\right)$ is obviously regularly open in $Y$.

Proof of (b). If $A^{\prime} \not \subset A$, then we have $A^{\prime} \not \subset \mathrm{Cl}_{Y}(A)$ because $A=$ $\operatorname{Int}_{Y}\left(\mathrm{Cl}_{Y}(A)\right)$. Therefore $A^{\prime} \cap\left[\mathrm{Cl}_{Y}(A)\right]^{c}$ is a non-void open set in $Y$, where $\left[\mathrm{Cl}_{Y}(A)\right]^{c}$ denotes the complement of $\mathrm{Cl}_{Y}(A)$. Since $X$ is dense in $Y$, there exists a point of $X$ contained in $A^{\prime} \cap\left[\mathrm{Cl}_{Y}(A)\right]^{c}$, and it follows that $A^{\prime} \cap X \not \subset A \cap X$. The first part of (b) is therefore true. The last part of (b) follows immediately from the first.

2. Paracompactness. Throughout the sequel, we shall restrict ourselves to consideration of Tychonoff spaces (completely regular $T_{1^{-}}$ spaces). A compactification of $X$ is a compact Hausdorff space containing $X$ as a dense subspace. The Stom-Cech compactification $\beta X$ is characterized among the compactifications of $X$ by the fact that every bounded continuous function on $X$ has a continuous extension over $\beta X^{5}$.

THEOREM 1. $X$ is paracompact if and only if for each compact set $F$ in $\beta X-X$ there is a surrounding ${ }^{6} V$ for $X$ such that

$$
\tilde{V} \cap \Delta_{F}=\phi,
$$

where $\bar{V}$ denotes the interior of the closure of $V$ taken in $\beta X \times \beta X$; $\tilde{V}=\operatorname{Int}_{\beta X \times \beta X}\left(\mathrm{Cl}_{\beta X \times \beta X}(V)\right)$, and $\Delta_{F}=\{(p, p) \in \beta X \times \beta X ; p \in F\}$.

Proof. (Necessity) Assume that $X$ is a paracompact space, and let $F$ be a compacts set contained in $\beta X-X$. Then, there is for each point $x \in X$ an open neighborhood (in $\beta X$ ) $U_{x}^{*}$ of $x$ such that $\mathrm{Cl}_{\beta X}\left(U_{x}^{*}\right)$ $\cap F=\phi$. Put $U_{x}=U_{x}^{*} \cap X$ and consider an open covering $\left\{U_{x}\right\}_{x \in X}$ of $X$. Take a locally finite open refinement $\left\{U_{\lambda}\right\}$ of $\left\{U_{x}\right\}_{x \in X}$, and let $\sum \varphi_{\lambda}=1$ be a locally finite partition of unity subordinate to $\left\{U_{\lambda}\right\}$. Put $d(x, y)=\sum\left|\varphi_{\lambda}(x)-\varphi_{\lambda}(y)\right|$ and put $V_{n}=\left\{(x, y) \in X \times X ; d(x, y)<1 / 2^{n}\right\}$. We shall show that $\tilde{V}_{1} \cap \Delta_{F}=\phi$, which will completes the proof.

Suppose, on the contrary, that there is a point $p \in F$ such that $(p, p) \in \tilde{V}_{1}$, then $U^{*}(p) \times U^{*}(p) \subset \tilde{V}_{1}$ for some open neighborhood (in $\beta X) U^{*}(p)$ of $p$, because $\tilde{V}_{1}$ is open in $\beta X \times \beta X$. Let $x$ be a point of $U(p)=U^{*}(p) \cap X$ (there is surely such a point, since $X$ is dense in $\beta X$ ), then there exists only a finite number of $\varphi_{\lambda}$ 's, say $\varphi_{1}, \cdots, \varphi_{n}$, which do not vanish at $x$. Put $H_{k}=\left\{y \in X ; \varphi_{k}(y)>0\right\}$, for $1 \leqq k \leqq n$. Clearly

5 C.f. [2] p. 833.

${ }^{6}$ We call $V$ a surrounding for $X$ if $V$ is a member of a uniformity for $X$ compatible with the topology of $X$. (= "entourage") 
$y \notin \bigcup_{k=1}^{n} H_{k}$ implies $d(x, y)>1$, and it follows that $U^{*}(p) \cap X \subset \bigcup_{k=1}^{n} H_{k}{ }^{7}$. Hence $p$ is contained in $\mathrm{Cl}_{\beta X}\left(\mathbf{U}_{k=1}^{n} H_{k}\right)$. On the other hand, $H_{k}$ is contained in some $U_{x}$ because $\left\{U_{\lambda}\right\}$ is a refinement of $\left\{U_{x}\right\}_{x \in X}$, and $\mathrm{Cl}_{\beta X}\left(U_{x}\right) \cap F=\phi$. Therefore, no point of $F$ is contained in $\mathrm{Cl}_{\beta X}\left(\bigcup_{k=1}^{n} H_{k}\right)$ $=\bigcup_{k=1}^{n}\left(\mathrm{Cl}_{\beta X}\left(H_{k}\right)\right)$. We have thus a contradiction. It follows that $\hat{V}_{1} \cap \Delta_{F}=\phi$.

(Sufficiency). Let $\left\{0_{\nu}\right\}$ be any open covering of $X$. For each $0_{\nu}$, we take (and fix) one open set $0_{\nu}^{*}$ (in $\left.\beta X\right)$ such that $0_{\nu}^{*} \cap X=0_{\nu}$. Put $F_{\nu}=\left[0_{\nu}^{*}\right]^{c}$, where $\left[0_{\nu}^{*}\right]^{c}$ denotes the complement of $0_{\nu}^{*}$ in $\beta X$, and put $F=\bigcap_{\nu} F_{\nu}$, then $F$ is a compact set contained in $\beta X-X$. By the hypothesis of our theorem, we can construct a sequence of surrounding $\left\{V_{n}\right\}$ such that $\hat{V}_{1} \cap \Delta_{F}=\phi$. Now, let us consider the uniform space $(X, \mathscr{U})$, where $\mathscr{U}=\left\{V_{n}\right\}$, and let $\tau$ be the uniform topology of $\mathscr{U}$. It is clear that topological the space $(X, \tau)$ is pseudo-metrizable hence is paracompact. $^{8}$ Let $d(x, y)$ be a pseudo-metric for $X$ such that $\{(x, y) \in X \times X$; $d(x, y)<1\} \subset V_{1}$, and put $W_{n}=\left\{(x, y) \in X \times X ; d(x, y)<1 / 2^{n}\right\}$. Since $V_{1} \supset W_{1}$ implies $\tilde{V}_{1} \supset \tilde{W}_{1}$ and since $\tilde{V}_{1} \cap \Delta_{F}=\phi$, we have $\tilde{W}_{1} \cap \Delta_{F}=\phi$. Consider an open covering $\left\{W_{3}(x)\right\}_{x \in X}$ of $(X, \tau)$ and let $\left\{U_{\lambda}\right\}$ be a locally finite open refinement of $\left\{W_{3}(x)\right\}_{x \in X}$. Since the original topology of $X$ is stronger than $\tau,\left\{U_{\lambda}\right\}$ is necessarily a locally finite open covering of $X$ with respect to the original topology of $X$.

We shall show presently that $\mathrm{Cl}_{\beta X}\left(U_{\lambda}\right) \cap F=\phi$ for each $U_{\lambda}$. Notice first that the restriction $d_{x}(y)$ of $d(x, y)$ on $x \times X$ is a bounded continuous function on $X$ with respect to the original topology and hence it has a continous extension $d_{x}^{*}$ over $\beta X$. Suppose that $\mathrm{Cl}_{\beta X}\left(U_{\lambda}\right)$ $\cap F \neq \phi$ for some $U_{\lambda}$, and let $p$ be a point of $\mathrm{Cl}_{\beta X}\left(U_{\lambda}\right) \cap F$. Since $U_{\lambda} \subset W_{3}\left(X_{0}\right)$ for some $x_{0} \in X, p$ is an accumulation point of $\{y \in X$; $\left.d\left(x_{0}, y\right)<1 / 2^{3}\right\}$ for some $x_{0} \in X$. Therefore $d_{x_{0}}^{*}(p) \leqq 1 / 2^{3}<1 / 2^{2}$, and there is a neighborhood (in $\beta X$ ) $0^{*}(p)$ of $p$ such that $d_{x_{0}}(y)<1 / 2^{2}$ for each $y \in 0(p)=0^{*}(p) \cap X$. It follows that $0(p) \times 0(p) \subset W_{1}$, and consequently we have $(p, p) \in 0^{*}(p) \times 0^{*}(p) \subset \operatorname{Int}_{\beta X \times \beta X}\left(\mathrm{Cl}_{\beta X \times \beta X}(0(p) \times 0(p))\right.$ $\subset \tilde{W}_{1}$. But this contradicts the above fact that $\tilde{W}_{1} \cap \Delta_{F}=\phi$, Hence $\mathrm{Cl}_{\beta X}\left(U_{\lambda}\right) \cap F=\phi$.

Thus, we have a locally finite open covering $\left\{U_{\lambda}\right\}$ of $X$ such that $\mathrm{Cl}_{\beta X}\left(U_{\lambda}\right) \cap F=\phi$ for each $\lambda$. Returning to the original covering $\left\{0_{\nu}\right\}$ of $X$, we find that $\left\{0_{\nu}^{*}\right\}$ covers $\mathrm{Cl}_{\beta X}\left(U_{\lambda}\right)$ for each $U_{\lambda}$, and, since $\mathrm{Cl}_{\beta X}\left(U_{\lambda}\right)$ is compact, there is a finite number of $0_{\nu}^{*}$ 's, say $0_{1}^{*}, \cdots, 0_{m}^{*}$ such that $\mathrm{Cl}_{\beta X}\left(U_{\lambda}\right) \subset \bigcup_{k=1}^{m} 0_{k}^{*}$. It follows that $U_{\lambda} \subset \bigcup_{k=1}^{m} 0_{k}$, and we have $U_{\lambda}=$ $\mathbf{\bigcup}_{k=1}^{m} H_{\lambda, k}$, where $H_{\lambda, k}=U_{\lambda} \cap 0_{k}$. Thus, each $U_{\lambda}$ can be represented as a finite union of open sets of the form $H_{\lambda_{k}}$. Constructing $H_{\lambda_{k}}$ for each $U_{\lambda}$ in this way, we have a locally finite open refinement $\left\{H_{\lambda, k}\right.$ ) of

7 By virtue of our lemma, it follows that $U(p) \times U(p) \subset \operatorname{Int}_{X \times X}\left(\mathrm{Cl}_{X \times X}\left(V_{1}\right)\right)$, and therefore $d(x, y) \leqq 1 / 2<1$ for each $y \in U(p)$.

8 See $\lceil\mathbf{1 0}\rceil$, p. 160. 
$\left\{0_{\nu}\right\}$. It follows that $X$ is paracompact.

From the proof of the preceding theorem, we obtain the following characterization of paracompactness.

CoRollary. $X$ is paracompact if and onl if for each compact set $F$ in $\beta X-X$ there is a locally finite open covering $\left\{U_{\lambda}\right\}$ of $X$ such that $\mathrm{Cl}_{\beta X}\left(U_{\lambda}\right) \cap F=\phi$. (Each $U_{\lambda}$ is a subset of $X$.)

The following theorem gives also a characterizotion of paracompactness.

THEOREM 2. $X$ is paracompact if and only if $X \times \beta X$ is normal.

Proof. The necessity of the condition is clear ${ }^{9}$. To prove the sufficiency, we have only to show that for each compact set $F$ in $\beta X-X$ there is a surrounding $V$ for $X$ such that $\tilde{V} \cap \Delta_{F}=\phi$, by virtue of Theorem 1 .

Let $F$ be a compact set contained in $\beta X-X$, then $X \times F$ and $\Delta_{X}$ are disjoint closed sets in $X \times \beta X$, and since $X \times \beta X$ is normal there are two open sets $U_{1}, W_{1}$ in $X \times \beta X$ such that $U_{1} \supset \Delta_{X}, W_{1} \supset X \times F$ and $U_{1} \cap W_{1}=\phi$. Put $U_{0}=\operatorname{Int}_{X \times \beta X}\left(\mathrm{Cl}_{X \times \beta X}\left(U_{1}\right)\right)$, then $U_{0}$ is a regularly open set in $X \times \beta X$ such that $U_{0} \supset \Delta_{X}$ and $U_{0} \cap(X \times F)=\phi$.

We now put $U=U_{0} \cap(X \times X)$, and we will show that $\tilde{U} \cap \Delta_{F}=\phi$, where $\tilde{U}$ is the interior of the closure of $U$ taken in $\beta X \times \beta X$ and $\Delta_{F}=\{(p, p) \in \beta X \times \beta X ; p \in F\}$. Suppose, on the contrary, that $\tilde{U} \cap$ $\Delta_{F} \neq \phi$, and let $(p, p)$ be a point of $\tilde{U} \cap \Delta_{F}$. Then, there is a neighborhood (in $\beta X) 0^{*}(p)$ of $p$ such that $0^{*}(p) \times 0^{*}(p) \subset \tilde{U}$. Let $x$ be a point of $0^{*}(p) \cap X$ (such a point exists, because $X$ is dense in $\beta X$ ), then $x \times 0^{*}(p) \subset \tilde{U}$ and we have $(x, p) \in\left(0^{*}(p) \times 0^{*}(p)\right) \cap(X \times \beta X)$ $\subset \tilde{U} \cap(X \times \beta X)$. On the other hand, it is true that $U_{0}=\tilde{U} \cap(X \times \beta X)$. In fact, $U=\bar{U} \cap(X \times X)$ by (a) of our lemma, and we have $U_{0} \cap(X \times X)$ $=U=\tilde{U} \cap(X \times X)=[\tilde{U} \cap(X \times \beta X)] \cap(X \times X)$. That is, the restriction of $U_{0}$ on $(X \times X)$ is identical with that of $\tilde{U} \cap(X \times \beta X)$. Therefore we have $U_{0}=\tilde{U} \cap(X \times \beta X)$ by (b) of the lemma, since both of $U_{0}$ and $\tilde{U} \cap(X \times \beta X)$ are regularly open in $X \times \beta X$. It follows that $(x, p) \in \tilde{U} \cap(X \times \beta X)=U_{0}$, but this contradicts the fact that $U_{0} \cap$ $(X \times F)=\phi$. Therefore $\tilde{U} \cap \Delta_{F}=\phi$.

We now consider the function $F(x, y) \in C(X \times \beta X)$ such that $F=0$ on $\Delta_{X}$ and $F=1$ outside of $U_{0}$ (such a function exists because $X \times \beta X$ is normal). Let $F_{x}$ be the restriction of $F$ on $x \times X$, and define a function $G\left(x, x^{\prime}\right)$ by letting

$$
G\left(x, x^{\prime}\right)=\left\|F_{x}-F_{x^{\prime}}\right\|=\sup _{z \in \beta X}\left|F(x, z)-F\left(x^{\prime}, z\right)\right| .
$$

9 See, [4], Th. 5 and Th. 1. 
It is easy to verify that $G$ is a continuous function on $X \times X^{10}$ and that

$$
\begin{gathered}
G\left(x, x^{\prime}\right) \geqq 0 \text { for each }\left(x, x^{\prime}\right) \in X \times X, \quad G(x, x)=0, \\
\quad G\left(x, x^{\prime}\right)=G\left(x^{\prime}, x\right), \\
G\left(x_{1}, x_{2}\right)+G\left(x_{2}, x_{3}\right) \geqq G\left(x_{1}, x_{3}\right) .
\end{gathered}
$$

and

Moreover, we have

$$
F\left(x, x^{\prime}\right)=F\left(x, x^{\prime}\right)-F\left(x^{\prime}, x^{\prime}\right) \leqq \sup _{z \in \beta X}\left|F(x, z)-F\left(x^{\prime}, z\right)\right|=G\left(x, x^{\prime}\right),
$$

and therefore $G\left(x, x^{\prime}\right)<1$ implies that $F\left(x, x^{\prime}\right)<1$. Put

$$
V=\left\{\left(x, x^{\prime}\right) \in X \times X ; G\left(x, x^{\prime}\right)<1\right\},
$$

then $V$ is evidently a surrounding for $X$ and we have $V \subset U$. It follows that $\tilde{V} \subset \tilde{U}$, and, since $\tilde{U} \cap \Delta_{F}=\phi$, we have $\tilde{V} \cap \Delta_{F}=\phi$. The proof is completed.

\section{REFERENCES}

1. B. J. Ball, The normality of the product of two ordered spaces, Duke Math. J., 24 (1957), 15-18.

2. E. Čech, On bicompact spaces, Ann. of Math., 38 (1937), 823-844.

3. H. H. Corson, The determination of paracompactness by uniformities, Amer. J. Math., 80 (1958), 185-190.

4. J. Dieudonné, Une generalization des espaces compacts, J. Math. Pures Appl., 23 (1944), 65-76.

5. C. H. Dowker, On countably paracompact spaces, Canadian J. Math., 3 (1951), 219-224.

6. M. Henriksen and J. R. Isbell, Some properties of compactifications, Duke Math. J., 25 (1958), 83-105.

7. E. Hewitt, Rings of real-valued continuous functions I, Trans. Amer. Math. Soc., 64 (1948), 45-99.

8. T. Isiwata, Normality of the product space of a countably compact space with its any compactification, Sci. Rep. Tokyo Kyoiku Daigaku, 6 (1958), 181-184.

9. G. 1. Kac, Topological spaces in which one may introduce a complete uniform structure, Math. Reviews, 17 (1956), 286.

10. J. L. Kelley, General topology, New York (1955).

11. S. Mrówka, Functionals on uniformly closed rings of continuous functions, Fund. Math., 46 (1958), 81-87.

12. H. Tamano, Some properties of the Stone-Cech compactification, J. Math. Soc. Japan, 12 (1960), 104-117.

KYOTO UNIVERSITY

10 Since $F(x, y)$ is a continuous function on $X \times \beta X$ and $\beta X$ is compact, there is for each $\varepsilon>0$ a neighborhood $U(x)$ of $x \in X$ such that $\left\|F_{x}-F_{x^{\prime}}\right\|<\varepsilon$ for each $x^{\prime} \in U(x)$. The continuity of $G$ follows from this fact by an easy calculation. 



\section{PACIFIC JOURNAL OF MATHEMATICS}

\section{EDITORS}

\author{
David Gilbarg \\ Stanford University \\ Stanford, California \\ F. H. Brownell \\ University of Washington \\ Seattle 5 , Washington
}

\author{
A. L. Whiteman \\ University of Southern California \\ Los Angeles 7, California \\ L. J. PAIGE \\ University of California \\ Los Angeles 24, California
}

\section{ASSOCIATE EDITORS}

\author{
E. F. BECKENBACH \\ T. M. CHERRY \\ D. DERRY
}
E. HEWITT
A. HORN
L. NACHBIN
M. OHTSUKA
H. L. ROYDEN
M. M. SCHIFFER

E. SPANIER

E. G. STRAUS

F. WOLF

\section{SUPPORTING INSTITUTIONS}

\author{
UNIVERSITY OF BRITISH COLUMBIA \\ CALIFORNIA INSTITUTE OF TECHNOLOGY \\ UNIVERSITY OF CALIFORNIA \\ MONTANA STATE UNIVERSITY \\ UNIVERSITY OF NEVADA \\ NEW MEXICO STATE UNIVERSITY \\ OREGON STATE COLLEGE \\ UNIVERSITY OF OREGON \\ OSAKA UNIVERSITY \\ UNIVERSITY OF SOUTHERN CALIFORNIA
}

\author{
STANFORD UNIVERSITY \\ UNIVERSITY OF TOKYO \\ UNIVERSITY OF UTAH \\ WASHINGTON STATE COLLEGE \\ UNIVERSITY OF WASHINGTON

AMERICAN MATHEMATICAL SOCIETY
CALIFORNIA RESEARCH CORPORATION
HUGHES AIRCRAFT COMPANY
SPACE TECHNOLOGY LABORATORIES
NAVAL ORDNANCE TEST STATION

Mathematical papers intended for publication in the Pacific Journal of Mathematics should be typewritten (double spaced), and the author should keep a complete copy. Manuscripts may be sent to any one of the four editors. All other communications to the editors should be addressed to the managing editor, L. J. Paige at the University of California, Los Angeles 24, California. ..

50 reprints per author of each article are furnished free of charge; additional copies may be obtained at cost in multiples of 50 .

The Pacific Journal of Mathematics is published quarterly, in March, June, September, and December. The price per volume (4 numbers) is $\$ 12.00$; single issues, $\$ 3.50$. Back numbers are available. Special price to individual faculty members of supporting institutions and to individual members of the American Mathematical Society: $\$ 4.00$ per volume; single issues, $\$ 1.25$.

Subscriptions, orders for back numbers, and changes of address should be sent to Pacific Journal of Mathematics, 2120 Oxford Street, Berkeley 4, California.

Printed at Kokusai Bunken Insatsusha (International Academic Printing Co., Ltd.), No. $6_{4}$ 2-chome, Fujimi-cho, Chiyoda-ku, Tokyo, Japan.

PUBLISHED BY PACIFIC JOURNAL OF MATHEMATICS, A NON-PROFIT CORPORATION

The Supporting Institutions listed above contribute to the cost of publication of this Journăl, but they are not owners or publishers and have no responsibility for its content or policies. 


\section{Pacific Journal of Mathematics}

\section{Vol. 10, No. $3 \quad$ November, 1960}

Glen Earl Baxter, An analytic problem whose solution follows from a simple

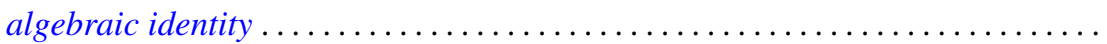

Leonard D. Berkovitz and Melvin Dresher, A multimove infinite game with linear payoff. .

Earl Robert Berkson, Sequel to a paper of A. E. Taylor ......................

Gerald Berman and Robert Jerome Silverman, Embedding of algebraic systems.... 767

Peter Crawley, Lattices whose congruences form a boolean algebra . . . . . ...... 777

Robert E. Edwards, Integral bases in inductive limit spaces . . . . . . . . . . . . . . .

Daniel T. Finkbeiner, II, Irreducible congruence relations on lattices . . . . . . . . . .

William James Firey, Isoperimetric ratios of Reuleaux polygons . . . . . . . . . . . 787

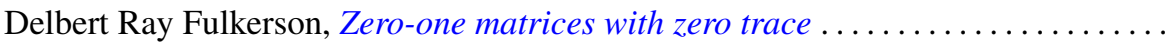

Leon W. Green, A sphere characterization related to Blaschke's conjecture........

Israel (Yitzchak) Nathan Herstein and Erwin Kleinfeld, Lie mappings in

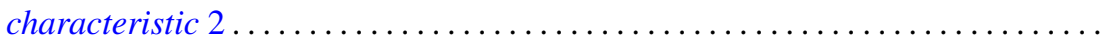

Charles Ray Hobby, A characteristic subgroup of a $p$-group .................

R. K. Juberg, On the Dirichlet problem for certain higher order parabolic

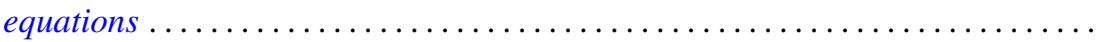

Melvin Katz, Infinitely repeatable games ......................

Emma Lehmer, On Jacobi functions . . . . . . . . . . . . . . . . . . . . . . . . .

D. H. Lehmer, Power character matrices

Henry B. Mann, A refinement of the fundamental theorem on the density of the sum of two sets of integers.

Marvin David Marcus and Roy Westwick, Linear maps on skew symmetric matrices: the invariance of elementary symmetric functions . .

Richard Dean Mayer and Richard Scott Pierce, Boolean algebras with ordered

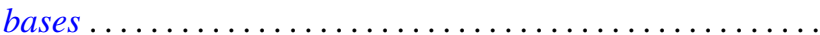

Trevor James McMinn, On the line segments of a convex surface in $E_{3} \ldots$

Frank Albert Raymond, The end point compactification of manifolds ..

Edgar Reich and S. E. Warschawski, On canonical conformal maps of regions of arbitrary connectivity

Marvin Rosenblum, The absolute continuity of Toeplitz's matrices...

Lee Albert Rubel, Maximal means and Tauberian theorems . .

Helmut Heinrich Schaefer, Some spectral properties of positive linear operators

Jeremiah Milton Stark, Minimum problems in the theory of pseudo-conformal transformations and their application to estimation of the curvature of the invariant metric.

Robert Steinberg, The simplicity of certain groups ...

Hisahiro Tamano, On paracompactness. .

Angus E. Taylor, Mittag-Leffler expansions and spectral theory .

Marion Franklin Tinsley, Permanents of cyclic matrices ...... . 